\title{
Citrinin and color analysis of angkak collected from several regions in Indonesia
}

\author{
${ }^{1,2}$ Ristiarini, S., ${ }^{2}$ Cahyanto, M.N., ${ }^{3}$ Widada, J. and ${ }^{2 *}$ Rahayu, E.S. \\ ${ }^{1}$ Faculty of Agricultural Technology, Widya Mandala Surabaya Catholic University, Jl. Dinoyo 42, \\ Surabaya 62825, Indonesia \\ ${ }^{2}$ Department of Food and Agricultural Product Technology, Faculty of Agricultural Technology, \\ Universitas Gadjah Mada, Jl. Flora No.1 Bulaksumur, Yogyakarta 55281, Indonesia \\ ${ }^{3}$ Faculty of Agriculture, Universitas Gadjah Mada, Jl. Flora, Bulaksumur, Yogyakarta 55281, \\ Indonesia
}

\section{Article history: \\ Article history: \\ Received: 17 February 2017 \\ Received in revised form: \\ 7 March 2017 \\ Accepted: 8 March 2017 \\ Available Online: \\ 10 March 2017}

\section{Keywords:}

Angkak

Citrinin

Color value

Monascus pigments

DOI:

http://doi.org/10.26656 fr.2017.2.021

\begin{abstract}
Angkak, a fermentation product of rice by Monascus sp., is used for natural food coloring, spices, and medicine by Indonesian people who believe in its pharmacological properties. However, Monascus sp. also produces a secondary metabolite, hepato-nephrotoxic mycotoxin citrinin. The biosynthesis of pigments and citrinin is generated from a tetraketide point in the polyketides pathway. This study aims to detect the levels of citrinin and examine its relationship with the color of angkak in Indonesia. Thirty samples were collected from eight different sites in Indonesia. ELISA method was used to detect the citrinin content. Meanwhile, the color analysis was based on the CIE $\mathrm{L}^{*} \mathrm{a} \mathrm{b}^{*}$ system and the measurement of its pigments was conducted using spectrophotometer UV-vis. All samples were grown on PDA (Potato Dextrose Agar) media. Mold contamination was found, ranging from $1.67 \%$ to $85.33 \%$. The results of citrinin content measurement of the angkak ranged from $17.94 \mathrm{ppm}$ to $142.74 \mathrm{ppm}$. The color measurement showed that the angkak color was various, from bright red $\left(\mathrm{L}^{*} 44.78\right.$, $\left.a^{*} 21.54, b^{*} 8.67\right)$ to very dark red ( $\left.L^{*} 35.62, a^{*} 17.32, b^{*} 5.43\right)$. The ethanol-soluble yellow (OD400) and red (OD500) pigment contents were in the ranges of $83.80 \mathrm{AU} / \mathrm{g}$ to $306.52 \mathrm{AU} / \mathrm{g}$ and 100.86 AU/g to $318.18 \mathrm{AU} / \mathrm{g}$, respectively. However, based on the Pearson correlation analysis, there was no correlation between the citrinin content and the color value of angkak.
\end{abstract}

\section{Introduction}

Angkak, also called red yeast rice (RYR), red mold rice (RMR), Anka, Ang-Khan, Anka-Koji, is a product of rice fermentation by Monascus purpureus, M. pilosus or M. ruber. For centuries, angkak has been consumed extensively in Asia as a natural coloring agent for many kinds of food, such as Chinese cheese, red wine, sausage and fish products (Lee et al., 2010; Dikshit and Tallapragada, 2011). Monascus produces six primary pigments, which are two yellow pigments (monascin and ankaflavin), two orange pigments (monascorubrin and rubropunctatin), and two red pigments (monascorubramin and rubropunctamin). They constitute the color characteristic of angkak (Rosenblitt et al., 2000). The pigments obtained from Monascus have long been used to dye meat and fish products in Asian countries. Angkak has been used in the manufacture of Nham sausage to replace nitrite/nitrate (Rojsuntornkitti et al., 2010) and many other products, such as nata (Sheu et al., 2000). In Indonesia, angkak has been used as traditional food colorings and spices, such as for cupcake and steamed glutinous rice, mung bean cake, chicken dishes and fried rice. Besides that, angkak has been used as a reducing agent of cholesterol and blood pressure level because angkak contain monacolin $\mathrm{K}$ and $\gamma$-amino butyric acid (GABA). Recently, angkak is also believed to have an anti-diabetic effect (Shi and Pan, 2010). In Indonesia, angkak is often used as a blood platelet-enhancing agent for patients with dengue fever. Despite those metabolites, Monascus also produces hepatic - nephrotoxic mycotoxin citrinin during fermentation. At the beginning, citrinin was isolated from Penicillium citrinum. However, now it is known that citrinin is also produced by other species of Penicillium, Aspergillus sp. and Monascus sp.

The color of citrinin isolated from Monascus purpureus is pale yellow (Blanc et al., 1995). The structure of citrinin and pigments were polyketide from the secondary metabolites of Monascus which have been synthesized by multifunctional enzymes of polyketide synthases. Hajjaj et al. (1999) stated that citrinin and pigment production by Monascus ruber begins at the branching point tetraketida in the polyketide pathway, whereas Penicillium sp. and 
Aspergillus sp. produce citrinin from pentaketide point. However, both the fungus do not produce pigments.

Fungus, especially Penicillium, Aspergillus, and Fusarium easily contaminate cereals and legumes during processing, distribution, and storage. In Indonesia, angkak is available at wet markets, supermarkets, pharmacies and traditional Chinese medicine shops with different storage conditions. The poor storage results in mold contamination of angkak which could increase the level of citrinin.

Angkak, as a traditional fermentation product, has not been included in the formal safety and health inspection. For that reason, it is necessary to examine the citrinin content in commercial angkak. This study aims to evaluate the occurrence of mycotoxin citrinin in angkak at the consumer level and determine the relationship with its color. Research on the relationship has never been done. The benefit of this research is to assist people in choosing angkak by color if there is a strong correlation between the color of angkak and its citrinin content.

\section{Materials and methods}

\subsection{Samples collection}

A total of 30 angkak samples from 30 vendors, each about 100 grams, were obtained from eight local markets (supermarket and wet market), traditional Chinese medicine shops and pharmacies in some regions in Indonesia: Java, Sumatera, Kalimantan, and Batam. The samples were collected in clean packs, labeled and stored in a cool room $\left(4^{\circ} \mathrm{C}\right)$.

\subsection{Preliminary detection of samples}

Preliminary detection of samples included the measurements of moisture content, water activity (aw) and the observation of mold contamination growth. The moisture content was determined by drying $1 \mathrm{~g}$ of ground samples using an oven at $105^{\circ} \mathrm{C}$ until a constant weight was obtained (A.O.A.C., 1995). The water activity was determined according to the standard operating procedure of Decagon pawkit water activity meter. The observation of mold contaminants was carried out by the direct method (Samson et al., 2010). A total of 100 grains of angkak was cultivated directly into ten Petri-dishes containing Potato Dextrose Agar (PDA) in which one Petri-dish contained 10 grains. The angkak was incubated at a temperature of $25^{\circ} \mathrm{C}$ and observed after 3 to 5 days of incubation. Three replications were conducted. The number of seeds contaminated was recorded in percentages. The observation of the mold contaminating red yeast rice was recognized by its morphological characters.

\subsection{Color measurement}

Color measurement was carried out according to the CR 400 manufacturer instructions (Minolta Co. Ltd., Osaka, Japan). Color measurement was in triplicate for each sample and calibrated with a white color standard plate CR 400 (L*a*b*) at the beginning of each session. The ground samples were poured in a cuvette with $4 \mathrm{~cm}$ diameter and $1.5 \mathrm{~cm}$ depth. The color space reading included L* (lightness) having a range of 0 (black) to 100 (white), a* (redness) indicating the direction of $+/-($ red/green $)$ and $b^{*}$ (yellowness) indicating the direction of $+/$ - (yellow/ blue). The hue angle ( ${ }^{\circ}$ hue) was determined as $\left(\tan ^{-1}\right.$ $\left.\mathrm{b}^{*} / \mathrm{a}^{*}\right)$ and the chroma as $\sqrt{ }(\mathrm{a} 2+\mathrm{b} 2)$ showing the color and saturation of color, respectively (Fabre et al., 1993; Teixieira et al., 2013). The average value of $L^{*} a^{*} b^{*}$ and $L^{*}$ hue, chroma of each sample being graphed three axes using XLstat 2016 to determine the distribution of the sample color values.

\subsection{Pigments measurement}

Ethanol-soluble pigments were analyzed according to Dikshit and Tallapragada (2011) with slight modification. One $\mathrm{g}$ of ground angkak was transferred in a $100 \mathrm{~mL}$ conical flask and mixed with $75 \%$ ethanol at a ratio of $5 \mathrm{~mL}$ per gram of sample. The content was mixed by shaking at $200 \mathrm{rpm}$ for 1 hour, filtered through Whatman No. 1 filter paper. The extract was centrifuged at $10,000 \mathrm{rpm}$ for 5 minutes and measured using spectrophotometer (Shimadzu UV - 1280) at wavelength $(\lambda)$ of 400 $\mathrm{nm}$ for yellow and $\lambda 500 \mathrm{~nm}$ for red pigment in the extract. The absorbance was converted into units of pigment per gram of sample (AU/g) by multiplying the dilution and the volume of extract and divided by the dry weight of the sample.

\subsection{Citrinin extraction and analysis}

Sample preparation and citrinin examination were carried out according to Ridascreen ${ }^{\mathbb{R}}$ Fast Citrinin (r-biopharm) procedure. Five $\mathrm{g}$ of ground angkak sample was transferred to $100 \mathrm{~mL}$ flask and added with $12.5 \mathrm{~mL}$ methanol $70 \%$, then homogenized for $3 \mathrm{~min}$ at $150 \mathrm{rpm}$. The extract was filtered through Whatman No. 1 filter paper. The filtrate $(1 \mathrm{~mL})$ was then diluted with $1 \mathrm{~mL}$ of deionized water. The treatment showed that five time dilution 
is proportional to the concentration standard. More dilution was needed when the reading of the samples is over the highest standards value of $405 \mathrm{ppb}$. A 50 $\mu l$ prepared samples or standards were transferred to micro titer wells coated with citrinin. Anti-citrinin antibody, enzyme conjugate solution (secondary antibody labeled with peroxidase), substrate (chromogenic solution) was added to complete ELISA procedure. The stop solution contains $1 \mathrm{~N}$ sulfuric acid which changed the solution from blue to yellow. Absorbance at wavelength $450 \mathrm{~nm}$ value was recorded in a micro plate reader (optic ivymen system 2100-C). The limit detection was $15 \mathrm{ppb}$. The absorbance values were converted to levels of citrinin by using the software of Ridasoft Win.NET - FAST citrinin. The tests were performed twice and the data were presented as a mean $\pm \mathrm{SD}$.

\subsection{Statistical analyses}

All of the parameter data were shown as mean and \pm standard deviation (SD). The mapping of color value scatters using Kohonen's self-organizing maps (SOM) in XLstat 2016. The correlation between citrinin content and hue of angkak was analyzed by Pearson product moment correlation using Excel program.

\section{Results and discussion}

\subsection{Preliminary detection of samples}

Preliminary detection of samples was to analyze of the sample conditions from the stores. Sampling was carried out from January to July 2013 and storage conditions were noted. Some shops were equipped with air-conditioning systems while others operated in the ambient air temperature or open-air surrounding. Some shops store angkak in a big jar while others store it in a plastic packaging with or without product information as shown in Table 1. Variations of storage condition might have impacts on the mold contamination.

\subsection{Moisture content and $A_{w}$}

The examination of the moisture content of 30 samples showed that the moisture content was around $10.92( \pm 0.64) \%$ with a range from $9.59( \pm$ $0.2) \%$ to $12.85( \pm 0.3) \%$ wet basis as shown in Table 1. The moisture content of angkak is correlated with the end process and storage. Angkak was dried until the moisture content was around 9-10\% after fermentation in order to have a long shelf life. The proximate composition of angkak was $72.10 \%$ carbohydrate, $11.6 \%$ protein, $1.58 \%$ lipid, and $0.45 \%$ ash (Kumari et al., 2009). However, the water activity of a product was a predominant factor in determining the shelf life of the product related to microbial contamination. Warehouse fungi growth require relative humidity of at least $65 \%$ or a water activity $\left(\mathrm{a}_{\mathrm{w}}\right)=0.65$ which is equivalent to an equilibrium moisture content of $13 \%$ in grains (Atanda et al., 2011). The water activity of the samples of angkak is in the range of 0.75 to 0.8 . The range allows fungi to grow well, especially if supported by appropriate growth temperature.

Table 1. Sources and conditions of samples

\begin{tabular}{|c|c|c|c|c|c|c|}
\hline Region & Shops & $\begin{array}{c}\text { Room } \\
\text { Temperature }\end{array}$ & Package & Code & $A_{w}$ & $\begin{array}{c}\text { Moisture } \\
\text { content (\%) }\end{array}$ \\
\hline \multirow[t]{9}{*}{ Jakarta } & TCMS & OAS & SPBI & JK1 & 0.80 & $9.59 \pm 0.20$ \\
\hline & Pharmacy & $\mathrm{AC}$ & SPBNI & $\mathrm{JK} 2$ & 0.78 & $10.47 \pm 0.04$ \\
\hline & TCMS & OAS & SPBNI & JK3 & 0.78 & $11.23 \pm 0.34$ \\
\hline & TCMS & OAS & SPBNI & JK9 & 0.77 & $11.59 \pm 0.39$ \\
\hline & TCMS & OAS & SPBNI & JK10 & 0.77 & $10.36 \pm 0.03$ \\
\hline & TCMS & OAS & SPBNI & JK22 & 0.80 & $11.20 \pm 0.16$ \\
\hline & TCMS & OAS & SPBI & $\mathrm{JK} 23$ & 0.78 & $10.71 \pm 0.16$ \\
\hline & TCMS & OAS & SPBNI & JK25 & 0.80 & $9.98 \pm 0.29$ \\
\hline & TCMS & OAS & SPBNI & JK26 & 0.78 & $10.64 \pm 0.02$ \\
\hline \multirow[t]{2}{*}{ Cikarang } & TCMS & $\mathrm{AC}$ & SPBNI & CK11 & 0.77 & $10.01 \pm 0.09$ \\
\hline & Pharmacy & $\mathrm{AC}$ & SPBI & CK24 & 0.78 & $10.33 \pm 0.30$ \\
\hline \multirow[t]{5}{*}{ Semarang } & TCMS & OAS & SPBNI & SM4 & 0.76 & $10.26 \pm 0.04$ \\
\hline & TCMS & OAS & BJ & SM5 & 0.76 & $10.78 \pm 1.36$ \\
\hline & TCMS & OAS & SPBNI & SM6 & 0.76 & $10.59 \pm 1.38$ \\
\hline & TCMS & OAS & BJ & SM7 & 0.77 & $11.22 \pm 0.98$ \\
\hline & TCMS & OAS & SPBNI & SM8 & 0.76 & $10.68 \pm 0.76$ \\
\hline \multirow[t]{7}{*}{ Yogyakarta } & TCMS & OAS & BJ & YK16 & 0.78 & $10.59 \pm 0.07$ \\
\hline & TCMS & OAS & SPBNI & YK17 & 0.76 & $10.40 \pm 1.39$ \\
\hline & TCMS & OAS & SPBNI & YK18 & 0.76 & $11.52 \pm 0.86$ \\
\hline & TCMS & OAS & SPBNI & YK19 & 0.77 & $10.99 \pm 0.90$ \\
\hline & TCMS & OAS & SPBNI & YK20 & 0.77 & $10.58 \pm 1.17$ \\
\hline & SM & $\mathrm{AC}$ & SPBI & YK21 & 0.76 & $11.01 \pm 0.85$ \\
\hline & SM & $\mathrm{AC}$ & SPBI & YK27 & 0.76 & $11.70 \pm 0.05$ \\
\hline \multirow[t]{4}{*}{ Surabaya } & WM & OAS & SPBNI & SB12 & 0.78 & $11.64 \pm 0.03$ \\
\hline & WM & OAS & BJ & SB13 & 0.75 & $11.33 \pm 0.06$ \\
\hline & TCMS & OAS & SPBNI & SB14 & 0.75 & $11.35 \pm 0.04$ \\
\hline & SM & $\mathrm{AC}$ & SPBI & SB15 & 0.77 & $11.30 \pm 0.10$ \\
\hline Padang & SM & $\mathrm{AC}$ & SPBNI & PD28 & 0.76 & $11.28 \pm 0.75$ \\
\hline Pontianak & SM & $\mathrm{AC}$ & SPBNI & PN29 & 0.75 & $12.85 \pm 0.30$ \\
\hline Batam & WM & OAS & SPBNI & BT30 & 0.79 & $11.48 \pm 0.40$ \\
\hline
\end{tabular}

Abbreviation: TCMS: Traditional Chinese Medicine Shop, SM: Supermarket, WM: Wet market, OAS: open-air surrounding, AC: air-conditioning, SPBI: a seal plastic bag with information of the product, SPBNI: a seal plastic bag no information of the product, BJ: Big information of the product, SPBNI: a seal plastic bag no inform
jar. Moisture content data are represented as mean $(n=3) \pm$ S.D.

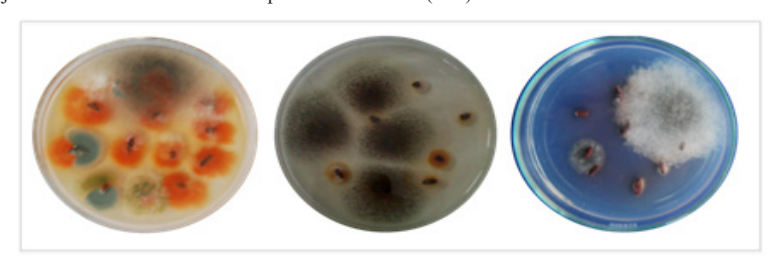

Figure 1. Mold contaminant of angkak grown on PDA medium for 3-5 days, $25^{\circ} \mathrm{C}$.

The orange is Monascus sp. used as a starter to produce angkak 


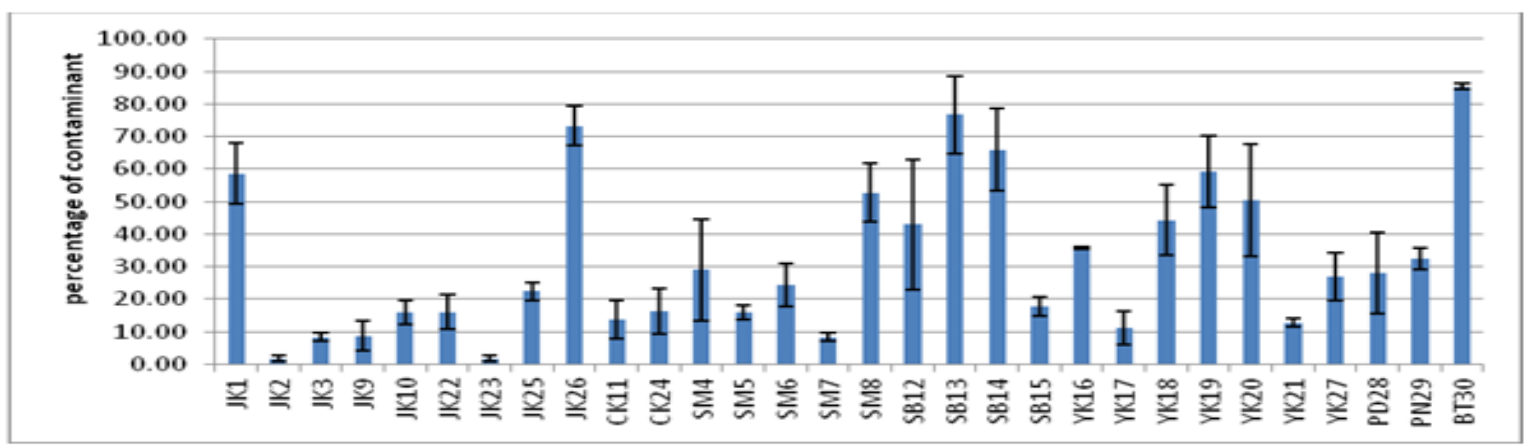

Figure 2. Percentage of mold contaminant on samples. The vertical bar represents S.D. $(n=3)$.

\subsection{Mold contaminant}

All of the samples were suspected to be contaminated by one or more species of the mold such as Mucor, Rhizopus, Penicillium and Aspergillus as shown in Figure 1 with a range of $1.63( \pm 1.15) \%$ to $85.33( \pm 1.15) \%$ (Figure 2$)$. The contamination indicates poor processing, storage or distribution of the angkak. The fungi are able to grow easily in cereal or high carbohydrate materials when the water activity is sufficient. Samsudin and Abdullah (2012) found that commercial angkak in Selangor, Malaysia is also contaminated by Penicillium chrysogenum, Aspergillus niger and Aspergillus flavus. Aspergilli can be easily grown in dry food with aw $0.84-0.91$ and appropriate storage conditions (Nugroho et al., 2013). Some species of Aspergillus and Penicillium produce mycotoxin that is ochratoxin and citrinin, respectively. Suspected fungal contamination can increase the levels of citrinin in angkak. The problem could be minimized by washing the angkak with a disinfectant solution $(\mathrm{NaOCl}$ solution $0.4 \%)$. The washing could release the contaminant fungus, but not Monascus. The study shows that the occurrence of citrinin contaminating angkak after processing, during storage and distribution. There was no contamination in angkak treated by washing with a hypochlorite solution.

\subsection{Color value and pigments}

Monascus produces at least six pigments which consist of red, orange and yellow colors as its secondary metabolites during fermentation. The yield of the pigments is determined by Monascus strains, the composition of growth media, environment conditions and length (duration) of fermentation. The results showed that there was a little variation in red color of angkak sold in Indonesia. The variation of colors from angkak is indicated by its position on a three-axis graph, L* (lightness), a* (redness), and $\mathrm{b}^{*}$ (yellowness), which is a constituent component
Table 2. The $\mathrm{L}^{*}, \mathrm{a}^{*}, \mathrm{~b}^{*}$, hue and chroma of angkak

\begin{tabular}{lccc}
\hline & Minimum & Maximum & Mean $\pm \mathrm{SD}$ \\
\hline $\mathrm{L}^{*}$ (lightness) & 35.62 & 44.78 & $39.00 \pm 1.78$ \\
$\mathrm{a}^{*}$ (redness) & 17.07 & 21.91 & $19.76 \pm 1.29$ \\
$\mathrm{~b}^{*}$ (yellowness) & 5.43 & 8.85 & $7.10 \pm 0.83$ \\
${ }^{\circ}$ hue & 17.40 & 22.52 & $19.70 \pm 1.2$ \\
chroma & 18.14 & 23.55 & $21.00 \pm 1.44$ \\
\hline
\end{tabular}

color based on the CIE (Commission Internationale d'Eclairage) L*a*b* (CIELAB) system (Figure 3A). The component of color value, i.e. $L^{*}, a^{*}, b^{*}$, hue and chroma, are shown in Table 2. The relationships of $\mathrm{L}^{*} \mathrm{a}^{*} \mathrm{~b}$, are nonlinear and any perceptual color differences are correlated to the Euclidean distance between two colors in the L*a*b* spaces (Teixeira et al., 2013). The study reveals that there was the longest distance plot between the SM8 and the YK16 on three-axes coordinates. It showed that the color of SM8 differs significantly from YK16. The color of the SM8 is formed by L*: $44.78 \pm 0.16, a^{*}: 21.54$ $\pm 0.13, b^{*}: 8.67 \pm 0.07$ while the color of the YK16 is compiled by $L^{*}: 35.62 \pm 0.1$, a*: $17.32 \pm 0.23, b^{*}$ : $5.43 \pm 0.08$.

The color can be expressed in terms of hue (color), lightness (brightness) and saturation (vividness). Hue angle (h) is expressed in degree, starting at the $+\mathrm{a}^{*}$ axis: $0^{\circ}\left(+\mathrm{a}^{*}\right)-90^{\circ}\left(+\mathrm{b}^{*}\right)$ would be red - yellow, $180^{\circ}$ $\left(-a^{*}\right)-270^{\circ}\left(-b^{*}\right)$ would be green - blue. The value of chroma $\mathrm{C}^{*}$ is 0 at the center and increases according to the distance from the center. The hue angle value for the product of Monascus is $0^{\circ}-30^{\circ}$ which indicates red-purple to red based on color space. Based on Kohonen's self-organized map (SOM) diagram on the hue, chroma, and L* (Figure 3B), there are groups with a different color of angkak. The bright red of angkak group consists of SM8, SM4, JK22, SB14 and the very dark red consists of YK16 and YK20.

The color variation is influenced by the variation of pigment productions for fermentation. Pigments are secondary metabolites; their formation is affected by Monascus strains, substrate composition, environmental factors and length of fermentation. 
A.

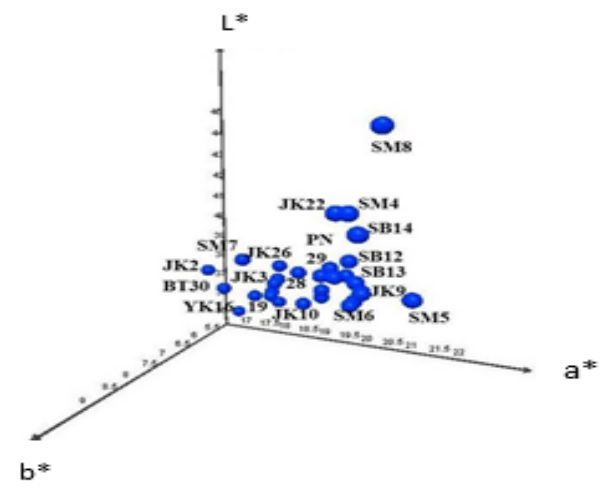

B.

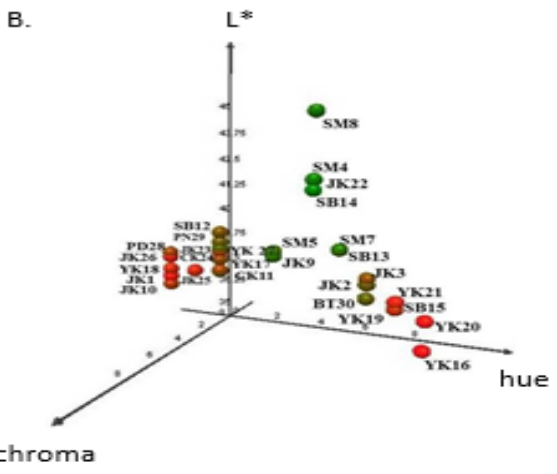

Figure 3. Scatter of $L^{*} a * b *$ values (A) and its self's organizing maps (SOM) of $L^{*}$ hue, chroma (B). The data were mean from three replicates.

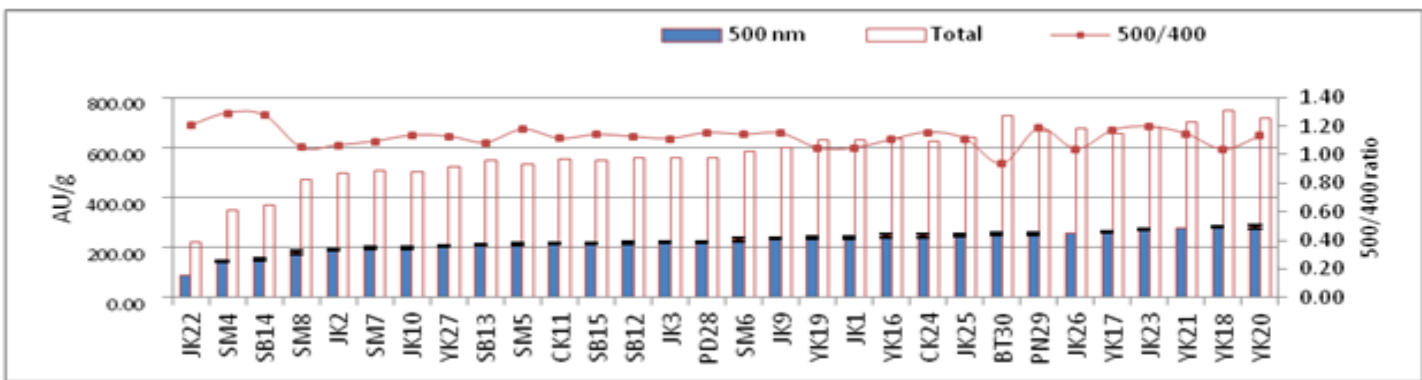

Figure 4. Specific absorbance ( $500 \mathrm{~nm}, \mathrm{AU} / \mathrm{g}$ ), total pigment and pigment ratio of A500 to A400 of $75 \%$ ethanol extract soluble pigments. Data were expressed as mean $(n=3)$ with error bars as standard deviation.

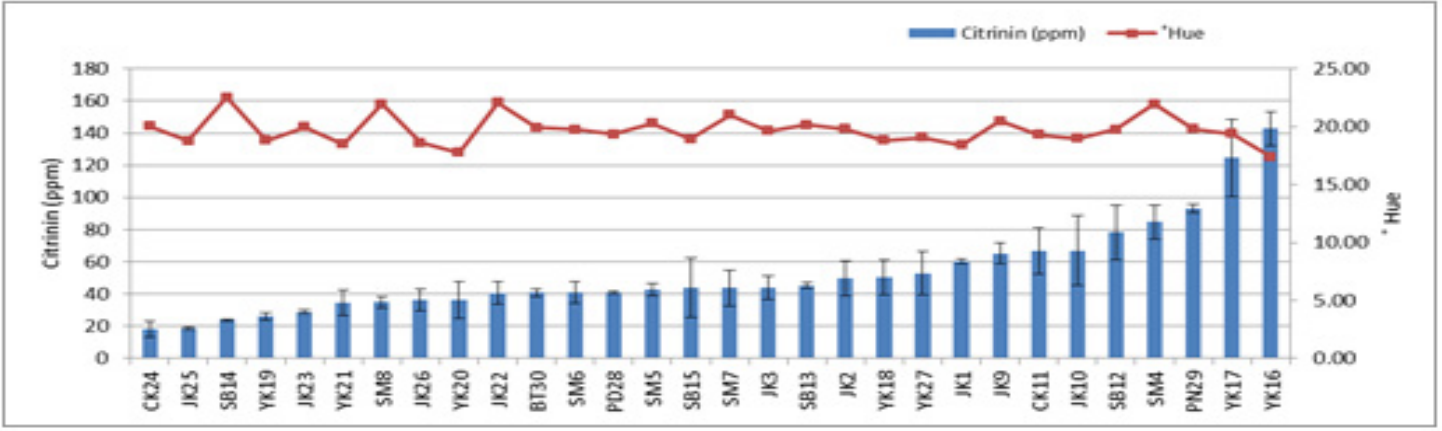

Figure 5. Citrinin content and hue of angkak. All measurements were carried out in triplicate, and data were expressed as mean with error bars as standard deviation.

Some researchers have shown that the variation of substrate such as rice varieties, supplementation of sugar, amino groups and minerals in substrate influences the total pigment variation produced by Monascus sp. (Carvalho et al., 2007; Chairote et al., 2007; Babitha et al., 2006; Lian et al., 2007, Nimnoi and Limyong, 2011; Kamalam et al., 2012). Similar to the color of angkak, the results of specific absorbance $(\mathrm{AU} / \mathrm{g})$ of red pigments extracted with $75 \%$ ethanol showed that the samples SM8, SM4, JK22 and SB14 contain lower red pigments and total pigments, although the absorbance ratios at $\lambda 500$ $\mathrm{nm}$ and $\lambda 400 \mathrm{~nm}$ are higher than others as shown in Figure 4. Similar results are shown by YK20 and YK18.

\subsection{Citrinin}

In the present study, all of the samples $(n=30)$ contain citrinin with a range from $17.94( \pm 5.08)$ ppm to $124.68( \pm 10.71) \mathrm{ppm}$, and $37 \%$ of them was more than $50 \mathrm{ppm}$ as shown in Figure 5. The level of citrinin in red yeast rice at a commercial rate varies greatly, ranging from non-detected by using HPLC (Liu and Xu, 2013) to 189 ppm (Gordon et al., 2010). Such variations are influenced by Monascus strains, fermentation substrate, and the environment. Citrinin is a secondary toxic benzopyran metabolite produced and secreted by some Aspergillus, Penicillium, especially P. citrinum and Monascus species. The level of citrinin in angkak may also be influenced by the type of contaminating mold that can produce 
citrinin. Not all angkak samples were contaminated by Aspergillus and Penicillium. However, the level of mold contaminants was not correlated with higher levels of citrinin in angkak $\left(\mathrm{R}^{2}=0.0166\right)$. Milani (2013) noted that toxin production occurs at a temperature of $20-30^{\circ} \mathrm{C}$ and $0.75-0.85 \mathrm{a}_{\mathrm{w}}$, depending on the species. In animals and humans, the toxin accumulates in the kidneys and can cause severe renal failure. Flajs and Peraica (2009) noted that the LD50 citrinin in mice per oral is $50 \mathrm{mg} \mathrm{kg}^{-1}$ (body weight), while Chang et al. (2011) suggest that citrinin with concentration up to $12.5 \mathrm{ppm}$ is not cytotoxic against human cell cultures. However, it disrupts the order of the microtubule and causes instability of the number of chromosomes in human blood.

The maximum limit consumption of angkak has not been set by Indonesian national agency of drugs and foods controls. Meanwhile, Taiwan and Japan have already regulated the use of angkak at less than $2 \mathrm{ppm}$ and $0.2 \mathrm{ppm}$ (Pattanagul et al., 2007; Lee et al., 2010). Samsudin and Abdullah (2012) stated that citrinin is allowed to $5 \mathrm{ppm}$ in Malaysia. Although acute exposure due to citrinin is very rarely, the consumption of foods with a low level of citrinin for a long time can cause problems. Citrinin is retained over $90 \%$ during dry heating or wet heating but it is mostly removed by $50 \%$ ethanol acidified with $0.75 \%$ phosphate (Lee et al., 2007). The dose for angkak consumption should be set in regulations issued by the Agency for Drug and Food Control of Indonesia.

The results of correlation analysis in this study show that there is no correlation between citrinin content and hue (color value) or red pigment yield, respective with $\mathrm{R}^{2}=0.0465$ and $\mathrm{R}^{2}=0.003$. Biosynthesis citrinin and pigments in Monascus ruber start from the branching point tetraketida compound in polyketide synthase pathway (Hajjaj et al., 1999). Although the formation of pigment and citrinin derived from the same compound, the results of the two compounds were not related linearly.

\section{Conclusion}

All angkak at the consumer level in Indonesia contains a high level of citrinin. The level of citrinin in angkak is not correlated either with its color value or red pigment. Thus, consumers can not choose angkak with low level of citrinin only by its color. Research on other mycotoxins in angkak at the consumer level needs to be done due to mold contaminants during storage or distribution.

\section{Conflict of interest}

None.

\section{Acknowledgment}

The research was funded by Widya Mandala Surabaya Catholic University as part of the funds for the postgraduate study.

\section{References}

A.O.A.C. (1995). Official methods of analysis. Association of Official Analytical Chemists. Washington, DC.

Atanda, S. A., Pessu, P. O., Agoda, S., Isong, I. U., Adekalu, O. A., Echendu, M. A. and Falade, T. C. (2011). Fungi and mycotoxins in stored foods. African Journal of Microbiology Research, 5(25), 4373-4382.

Babitha, S., Soccol, C.R. and Pandey, A. (2006). Jackfruit seed - a novel substrate for the production of Monascus pigments through solid-state fermentation. Food Technology and Biotechnology, 44(4), 465-471.

Blanc, P. J., Laussac, J., Le Bars, P., Le Bars, M. O., Loret, A., Pareilleux, D., Prome, J. C., Prome, A. L., Santerre, A. L. and Goma, G. (1995). Characterization of monascidin A from Monascus as citrinin. International Journal of Food Microbiology, 27, 201213.

Carvalho, J.C., Oishi, B.O., Woiciechowski, A.L., Pandey, A., Babitha, S. and Soccol, C. (2007). Effect of substrates on the production of Monascus biopigments by solid-state fermentation and pigment extraction using different solvents. Indian Journal of Biotechnology, 6, 194-199.

Chairote, E., Chairote, G., Wongpornchai, S. and Lumyong, S. (2007). Preparation of red yeast rice using various Thai glutinous rice and Monascus purpureus CMU001 isolated from commercial Chinese red yeast rice sample. KMITL Science and Technology Journal, 7, 28-37.

Chang, C.H., Yu, F.Y., Wu, T.S., Wang, L.T. and Liu, B.H. (2011). Mycotoxin citrinin induced cell cycle G2/M arrest and numerical chromosomal aberration associated with disruption of microtubule formation in human cells. Toxicological Sciences, 119(1), 84-92.

Dikshit, R. and Tallapragada, P. (2011). Monascus purpureus: A potential source for natural pigment production. Journal of Microbiology and Biotechnology Research, 1(4), 164-174.

Fabre, C.E., Santerre, A.L., Loret, M.O., Baberian, R., Pareilleux, A., Goma, G. and Blanc, P.J. (1993). Production and food application of the red pigments of Monascus ruber. Journal of Food Science, 58(5), 1099-1110.

Flajs, D. and Peraica, M. (2009). Toxicological properties of citrinin. Archives of Industrial Hygiene and Toxicology Journal, 60, 457-464. 
Gordon, R.Y., Cooperman, T., Obermeyer, W.and Becker, D.J. (2010). Marked variability of Monacolin levels in commercial red yeast rice products. Archives Internal Medicine Journal 170(19), 1722-1727.

Hajjaj, H., Klaebe, A., Loret, M.O., Goma, G., Blanc, P.J. and Francois, J. (1999). Biosynthetic pathway of citrinin in the filamentous fungus Monascus ruber as revealed by $13 \mathrm{C}$ nuclear magnetic resonance. Applied and Environmental Microbiology, 65(1), 311-314.

Kamalam, J.N., Anburaj, J., Kuberan, T., Sundaravadivelan, C., Kumar, P., Starlin, T., Sevi, A.T. and Devi, M.V. (2012). DNA amplification and characterization of pigment-producing gene from Monascus ruber. European Journal of Experimental Biology, 2(2), 427435.

Kumari, H.P.M., Naidu, K.A., Vishwanatha, S., Narasimhamurthy, K. and Vijayalakshmi, G. (2009). Safety evaluation of Monascus purpureus red mould rice in albino rats. Food and Chemical Toxicology, 47, 1719-1746.

Lee, C.L., Hung, H.K., Wang, J.J. and Pan, T.M. (2007). Improving the ratio of monacolin $\mathrm{K}$ to citrinin production of Monascus purpureus NTU 568 under dioscorea medium through the mediation of $\mathrm{pH}$ value and ethanol addition. Journal of Agricultural and Food Chemistry, 55, 6493-6502.

Lee, C.H., Lee, C.L. and Pan, T.M. (2010). A 90-D toxicity study of Monascus-fermented products including high citrinin level. Journal of Food Science 75(5), T91-T97.

Lin, Y.L., Wang, T.H., Lee, M.H. and Su, N.W. (2007). Biologically active components and nutraceuticals in the Monascus-fermented rice: a review. Applied Microbiology and Biotechnology, 77, 965-973.

Liu, R., and $\mathrm{Xu}, \mathrm{B}$. (2013). Optimization of extraction conditions of citrinin from red yeast rice by orthogonal design and quantification of citrinin by highperformance liquid chromatography. Food Analitycal Methods, 6, 677-682.

Milani, J.M. (2013). Ecological condition affecting mycotoxin production in cereal: a review. Veterinarni Medicina, 58(8), 405-411.

Nimnoi, P., Pongsilp, N. and Lumyong, S. (2015). Utilization of agro-industrial products for increasing red pigment production of Monascus purpureus AHK12. Chiang Mai Journal of Science, 42(2), 331338.

Nugroho, A.D., Setyabudi, F. M. C. S., Salleh, B. and Rahayu, E.S. (2013). Ochratoxigenic black Aspergilli isolated from dried, agricultural products in Yogyakarta, Indonesia. Journal of Food Science and Engineering, 3, 472-480.

Pattanagul, P., Pinthong, R., Phianmongkhol, A. and Leksawasdi, N. (2007). Review of angkak production (Monascus purpureus). Chiang Mai Journal of Science, 34(3), 319-328.
Rojsuntonkitti, K., Jittrepotchi, N., Kongbogkerd, T. and Kraboun, K. (2010). Substitution of nitrite by Chinese red broken rice powder in Thai traditional fermented pork sausage (Nhamn). International Food Research Journal, 17, 153-161

Rosenblitt, A., Agosin, E., Delgado, J. and Ricardo, P-C. (2000). Solid substrate fermentation of Monascus purpureus: Growth, carbon balance, and consistency analysis. Biotechnology Progress, 16, 152-162.

Samson, R.A., Houbraken, J., Thrane, U., Frisvad, J.C., and Andersen, B. (2010). Food and Indoor Fungi. CBS-KNAW Fungal Biodiversity Centre Utrecht, The Netherlands.

Samsudin, N. I. P. and Abdullah, N. (2013). A preliminary survey on the occurrence of mycotoxigenic fungi and mycotoxins contaminating red rice at consumer level in Selangor, Malaysia. Mycotoxin Research, 29(2), 89-96.

Sheu, F., Wan, C.L. and Shyu, Y.T. (2000). Fermentation of Monascus purpureus on bacterial cellulose nata and the color stability of Monascus-nata complex. Journal of Food Science, 65(2), 342-345.

Shi, Y.C. and Pan, T.M. (2010). Anti-diabetic effects of Monascus purpureus NTU 568 fermented products on streptozotocin-induced diabetic rats. Journal of Agricultural and Food Chemistry, 58(13), 7634-7640.

Teixeira, C. C. C., Teixeira, G.A. and Freitas, L.A.P. (2012). Improving the production and CIELAB* color parameters of Monascus rubber pigments using a fractional design. Asian Journal of Biomedical and Pharmaceutical Sciences, 2(15), 62-68. 